Article

\title{
Room and High Temperature Tribological Performance of Multilayered TiSiN/TiN and TiSiN/TiN(Ag) Coatings Deposited by Sputtering
}

\author{
Filipe Fernandes ${ }^{1,2}\left(\mathbb{D}\right.$, Abbas AL-Rjoub ${ }^{1, *} \mathbb{1}$, Diogo Cavaleiro ${ }^{1}$, Tomas Polcar $^{2}$ and \\ Albano Cavaleiro ${ }^{1}$ (D) \\ 1 Department of Mechanical Engineering, CEMMPRE-Centre for Mechanical Engineering Materials and Processes, \\ University of Coimbra, Rua Luís Reis Santos, 3030-788 Coimbra, Portugal; filipe.fernandes@dem.uc.pt (F.F.); \\ diogoacavaleiro@gmail.com (D.C.); albano.cavaleiro@dem.uc.pt (A.C.) \\ 2 Department of Control Engineering, Czech Technical University in Prague, Technicka 2, 616627 Prague, \\ Czech Republic; polcar@fel.cvut.cz \\ * Correspondence: abbas.al-rjoub@dem.uc.pt
}

Received: 7 November 2020; Accepted: 4 December 2020; Published: 6 December 2020

\begin{abstract}
In this study, we compare the tribological performance of a multilayer TiSiN/Ti(Ag)N coating with a TiSiN/TiN coating with a similar $\mathrm{Si}$ content in order to demonstrate the effect of the solid lubricant phase, silver. For $\mathrm{Al}_{2} \mathrm{O}_{3}$ balls, the hardness and reduced modulus determine the tribological performance of the coatings for tests conducted at room temperature (RT) against $\mathrm{Al}_{2} \mathrm{O}_{3}$ balls. At $550^{\circ} \mathrm{C}$, the TiSiN/TiN coating failed, whereas the Ag-containing coating performed better due to the presence of $\mathrm{Ag}$ in the contact, which decreased the shear stress and, consequently, the friction. For tests against TiAl6V4 balls, the Ag-containing coating was always better than the TiSiN/TiN one. At $550^{\circ} \mathrm{C}, \mathrm{Ag}$ in the wear track prevented the adhesion of the oxidized Ti-alloy wear debris in the contact, favoring the adhesion of wear debris from the coating to both the coating and counterpart surfaces. No wear could be measured for the $700{ }^{\circ} \mathrm{C}$ tests for both coatings due to different reasons: (i) the presence of oxidized adhered material from the ball to the reference TiSiN/TiN coating surface protected from wear and (ii) the presence of Ag-agglomerated particles decreased the friction and minimized the adhesion wear of the counterpart for the TiSiN/TiN(Ag) coating.
\end{abstract}

Keywords: TiSiN/TiN(Ag) coatings; high-temperature tribology; wear resistance; wear mechanisms

\section{Introduction}

The continuous growth in mobility has placed an increasing demand on the transport industry to manufacture vehicles at a lower cost, while ensuring that they operate efficiently, are friendly to the environment and meet safety requirements [1]. This is particularly important in the aerospace and automotive industries, where the use of lightweight airframes, as well as the global improvement of materials' mechanical properties, encourage the integration of composite materials in a large number of structural components [1,2]. Nowadays, the demand for titanium alloys has steadily increased in such industries due to their excellent strength-to-weight ratio and electrochemical compatibility. Titanium alloys have outstanding physical-mechanical properties, but they are difficult to machine due to their high chemical reactivity, poor heat conductivity and low modulus of elasticity, which lead to lower production rates and increased tool wear [1,3-6]. The formation of built-up edges [5,7], springback effect [2], high heat stress [3] and variations in the chip thickness [3] are the main effects leading to the premature degradation of the tools. Several solutions have been suggested to improve the machinability of Ti alloys. These include (i) the use of standard coolants and lubricants or cryogenic cooling, (ii) use of tools with a high thermal conductivity, (iii) optimization of the machining conditions 
by evaluating the stress, temperature and vibration during production, and (iv) use of coated tools. In the latter, coatings deposited by sputtering processes could double the lifetime of the tools as compared to the uncoated ones [1-5,8]. However, the currently used tool coatings for machining titanium alloys cannot satisfy the requirements of high-speed machining and green manufacturing.

Recently, there has been a significant increase of interest for using self-lubricant hard coatings to protect and extend the lifetime of machining tools used to process hard-to-machine materials operating under dry machining conditions [4]. Any promising coating for this purpose should combine a high toughness, low friction, good wear resistance and thermal stability under high-temperature conditions $[9,10]$. The most common candidates are high oxidation resistant binary or ternary nitrides and carbonitrides of transition metals such as $\mathrm{Ti}$ [11,12], $\mathrm{Cr}$ [13], W [14] or Ni [15] alloyed with: (i) soft metals ( $\mathrm{Ag}, \mathrm{Au}$, $\mathrm{Cu}$, etc.); (ii) fluorides $\left(\mathrm{CaF}_{2}, \mathrm{BaF}_{2}\right.$ and $\left.\mathrm{CeF}_{3}\right)$; and (iii) metal oxides $\left(\mathrm{V}_{2} \mathrm{O}_{5}, \mathrm{Ag}_{2} \mathrm{Mo}_{2} \mathrm{O}_{7}\right)$. Independently of the coatings' configuration (monolayer, multilayer or nanocomposite), the friction was decreased and the wear resistance was improved (see comprehensive papers in the literature: Voevodin et al. [5], Zhu et al. [16] and Aouadi et al. [17]). However, in most cases, their performance failed at a high temperature due to the low oxidation resistance, and strong elemental diffusion to the surface with the consequent rapid depletion of the lubricious agent and the consequent loss of the low-friction tribolayer after short operating periods [10]. The control of the metal out-diffusion is now one of the major challenges for achieving suitable long-duration wear and friction properties without compromising the original properties of the host binary and ternary films. Therefore, one possible solution for this problem will be to use a dual phase structure, in which one of the phases could act as a diffusion barrier to the metal, which should be responsible for the lubrication. The TiSiN system is a possible solution. When this system is deposited as either a nanocomposite structure (nanosized TiN crystallites surrounded by an amorphous matrix of Si-N) or a multilayered structure (TiSiN layers intercalated with layers containing the lubricious element), the Si-N phase can work as an anti-diffusion barrier [18].

In our previous studies [11,19], we reported the influence of Ag alloying on the morphology, structure, mechanical properties, thermal stability and oxidation resistance of monolithic TiSiNAg and multilayered TiSiN/TiN(Ag) coatings deposited by sputtering. The thermal stability and oxidation resistance results revealed that the TiSiN system allowed the control of the diffusion of the lubricious element $(\mathrm{Ag})$ to the surface, being a promising system for use as self-lubricant coating for cutting applications.

This work compares the tribological performance of a TiSiN/TiN(Ag) multilayered coating without and with Ag alloying containing a similar Si concentration. Our aim is to demonstrate the effect of a solid lubricant phase, silver, on the tribological properties at a high temperature. The tribological tests were performed using a high-temperature pin-on-disk equipment sliding against two types of balls, $\mathrm{Al}_{2} \mathrm{O}_{3}$ and TiAl6V4, at room temperature, 550 and $700{ }^{\circ} \mathrm{C}$.

\section{Materials and Methods}

TiSiN/TiN and TiSiN/TiN(Ag) coatings with a similar Si concentration and period thickness $(\sim 34 \mathrm{~nm})$ were deposited by direct current (DC) reactive magnetron sputtering, working in unbalanced mode, to compare their tribological performance and the potential of Ag-alloyed TiSiN/TiN as a self-lubricant coating. Two targets $(20 \mathrm{~cm} \times 10 \mathrm{~cm})$ were used in the depositions: (i) a high purity Ti (99.9\%) target with 19 drilled holes of 5-mm diameter distributed in the erosion zone: 11 holes were filled with Ag pellets, and the remaining holes were filled with Ti pellets; and (ii) a high purity (99.9\%) composite $\mathrm{Ti}_{88} \mathrm{Si}_{12}$ (at.\%) target. The targets were positioned parallel to each other. WC-6 wt.\% Co substrates were used for the tribological tests and were ultrasonically cleaned in acetone and alcohol for 15 and $10 \mathrm{~min}$, respectively.

The base pressure of the chamber prior to the deposition was $\sim 4 \times 10^{-4} \mathrm{~Pa}$. Before the deposition, the substrates were etched for $50 \mathrm{~min}$ in an Ar atmosphere (pulsed bias of $500 \mathrm{~V}$ and frequency of $250 \mathrm{kHz}$ applied to the substrate's holder), with a shutter in front of the targets and applying $200 \mathrm{~W}$ 
to each of the targets. The interlayer (for improving the adhesion of the coatings to the substrates) consisted of two steps: (i) a 300-nm TiSi adhesive layer produced from the TiSi composite target when applying a power density of $6.5 \mathrm{~W} / \mathrm{cm}^{2}$, an Ar flow of $11 \mathrm{sccm}$, a DC pulsed bias of $-60 \mathrm{~V}$ and $250 \mathrm{kHz}$, and (ii) a 250-nm gradient TiSiN layer produced with an increasing $\mathrm{N}_{2}$ flow until the final pressure of $0.35 \mathrm{~Pa}$ was achieved, with a rotation speed of $18 \mathrm{rpm}$ and applying a power density of $6.5 \mathrm{~W} / \mathrm{cm}^{2}$, Ar flow of $11 \mathrm{sccm}$, and DC pulsed bias of $-60 \mathrm{~V}$ and $250 \mathrm{kHz}$. The main multilayer structure was grown by applying $6.5 \mathrm{~W} / \mathrm{cm}^{2}$ to each target, using $11 \mathrm{sccm}$ of Ar and $13 \mathrm{sccm}$ of N, applying a DC pulsed bias of $-60 \mathrm{~V}$ with a substrate rotation of $0.9 \mathrm{rpm}$ to ensure a multilayer structure with a period of $\sim 34 \mathrm{~nm}$. The deposition time of the main coatings was set at $1 \mathrm{~h}$ and $15 \mathrm{~min}$ for both coatings in order to produce coatings with approximately $3 \mu \mathrm{m}$ of total thickness including the inter/gradient layers.

A pin-on-disk tribometer from CSM Instruments was used to evaluate the tribological performance of the coatings at room temperature (RT) and $550{ }^{\circ} \mathrm{C}$ against $\mathrm{Al}_{2} \mathrm{O}_{3}$ balls; further tests were also performed with TiAl6V4 balls at RT, 550 and $700{ }^{\circ} \mathrm{C}$. Temperatures of 550 and $700{ }^{\circ} \mathrm{C}$ were selected as they were closer to the temperatures generated at contact during machining. $\mathrm{A} 5 \mathrm{~N}$ load and $\mathrm{Al}_{2} \mathrm{O}_{3}$ balls were used as a standard to evaluate the wear of the coatings at high temperatures. Therefore, this procedure allowed for the direct comparison with many other studies on hard coatings. TiAl6V4 balls were used to evaluate the potential use of these coatings for the machining of the TiAl6V4 alloy. The diameter of the balls was $6 \mathrm{~mm}$. The tests were performed with a load of $5 \mathrm{~N}$, a sliding speed of $10 \mathrm{~cm} \cdot \mathrm{s}^{-1}$ and a duration of 2500 cycles, with a total distance of $62.8 \mathrm{~m}$. In the case of tests conducted against $\mathrm{Al}_{2} \mathrm{O}_{3}$ balls at $550{ }^{\circ} \mathrm{C}$, the length of the tests was decreased to $12.6 \mathrm{~m}$ with 500 cycles to avoid the complete wearing out of the coating and the substrate exposure. The friction coefficient (COF) was continuously acquired during the tests. The volume loss due to wear was calculated with the help of a $3 \mathrm{D}$ profilometer, and the specific wear rate was calculated according to Archard's law [20]. After the tests, the wear mechanisms and wear debris were characterized by scanning electron microscopy (SEM) and energy dispersive X-ray spectroscopy (EDS), and they were correlated with the friction coefficient and wear rate values of the coatings and balls.

\section{Results}

An extensive discussion of the influence of Ag alloying on the structure and mechanical properties of multilayered TiSiN/TiN coatings can be seen in our previous publication [19]. However, Table 1 presents a summary of the coatings' denomination, chemical composition and mechanical properties. In this work, we will focus on the tribological performance.

Table 1. Coatings' denomination, chemical composition and mechanical properties.

\begin{tabular}{ccc}
\hline Sample Designation & TiSiN/TiN & TiSiN/TiN(Ag) \\
\hline Chemical composition (at. $\%)$ & $\mathrm{Ti}-46.1$ & $\mathrm{Ti}-42.3$ \\
& $\mathrm{Si}-4.6$ & $\mathrm{Si}-4.3$ \\
$\mathrm{~N}-49.3$ & $\mathrm{~N}-50.2$ \\
$\mathrm{Ag}-3.2$ \\
\hline Hardness $(\mathrm{H})(\mathrm{GPa})$ & - & $18 \pm 4$ \\
\hline Reduced modulus $(E)(\mathrm{GPa})$ & $26 \pm 4$ & $286 \pm 23$ \\
\hline Elastic strain to failure- $-\mathrm{H} / \mathrm{E}$ & $334 \pm 28$ & 0.062 \\
\hline Onset point of oxidation $\left({ }^{\circ} \mathrm{C}\right)$ & 0.078 & $700{ }^{\circ} \mathrm{C}$ \\
\hline Oxidation weight gain at $800{ }^{\circ} \mathrm{C}$ for $2 \mathrm{~h} \mathrm{mg} / \mathrm{cm}^{2}$ & $700{ }^{\circ} \mathrm{C}$ & 0.16 \\
\hline
\end{tabular}




\subsection{Friction Coefficient}

\subsection{1. $\mathrm{Al}_{2} \mathrm{O}_{3}$ Balls}

Figure 1a,b shows the friction coefficient (COF) of the coatings as a function of the number of cycles for the tests performed with $\mathrm{Al}_{2} \mathrm{O}_{3}$ balls at $\mathrm{RT}$ and $550{ }^{\circ} \mathrm{C}$, respectively. At room temperature, two different stages of the friction coefficient could be observed, the first of which could be related to a running-in, while in the second one a steady-state could be achieved. The friction coefficient at the running-in stage increased steeply from the initial value of 0.2 to 0.65 and 0.85 after 700 and 1000 cycles for TiSiN/TiN and TiSiN/TiN(Ag) coatings, respectively. For the latter, COF remained approximately constant until the end of the test, with a value close to 0.9 . For the reference coating, a slow increasing trend was observed, reaching a value of 0.85 , which was kept constant in the last 500 cycles of the test. Globally, the average friction coefficient of the Ag-containing coating was slightly higher than the $\mathrm{COF}$ of the reference coating. In the second stage of the curve, the reference coating showed small fluctuations in the friction coefficient value until the end of the test, which, according to the literature, could be attributed to the occurrence of plastic deformation of the film [21], as will be discussed later. The average COF of this multilayer fell in the range of the values reported in the literature for TiN and TiSiN deposited as monolayer films [22-25]. The Ag-containing coating displayed a very smooth and stable coefficient of friction during the steady-state when compared with the reference coating. In spite of the different shapes of the curves, in the final steady-state level the COF was very similar for both coatings.
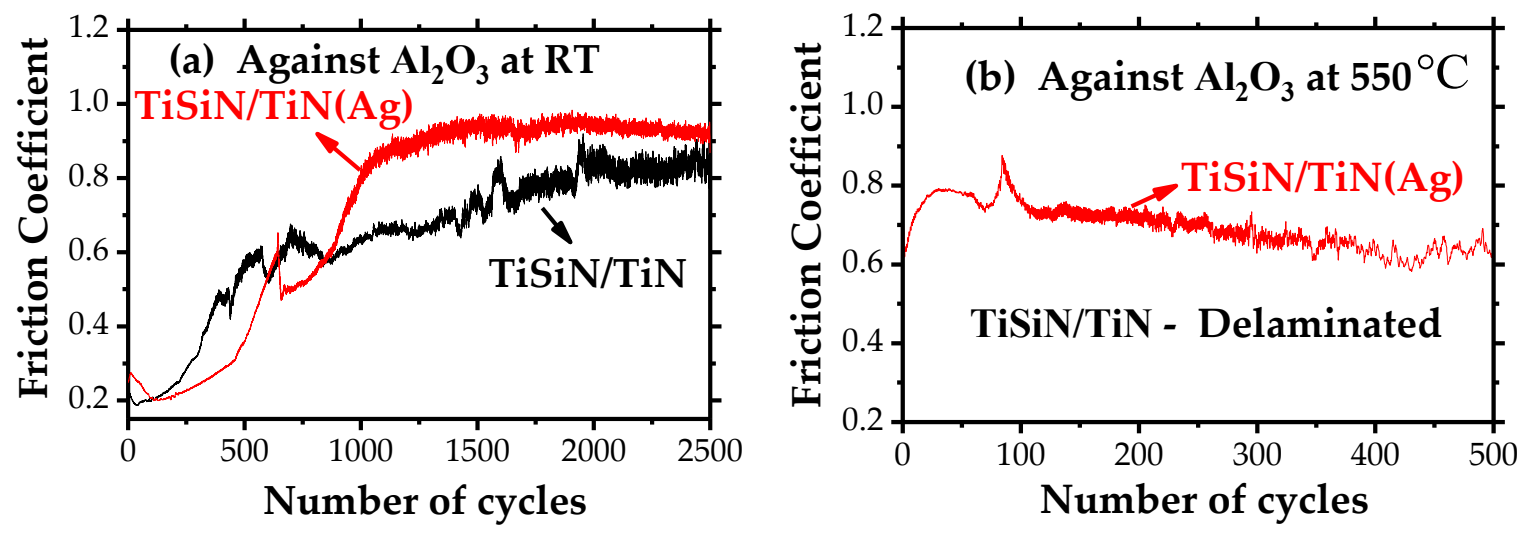

Figure 1. Friction coefficient of the TiSiN/TiN multilayer coatings with and without Ag addition as a function of the number of cycles tested against $\mathrm{Al}_{2} \mathrm{O}_{3}$ balls at: (a) $\mathrm{RT}$ and (b) $550{ }^{\circ} \mathrm{C}$.

For the test at $550{ }^{\circ} \mathrm{C}$, the reference coating was immediately worn out. The Ag-containing coating could survive at this temperature, but due to the extensive wear the number of cycles had to be decreased in order to avoid substrate exposure. Similar to the RT tests, two stages could be observed in the COF curve. However, the running-in period was very short, only 20 cycles, due to the easier adaption of the surface promoted by the temperature and the presence of $\mathrm{Ag}$ at contact, as will be discussed later. The average COF value was lower than when tested under RT conditions.

\subsubsection{TiAl6V4 Balls}

The friction coefficient values of the coatings as a function of the number of cycles tested against TiAl6V4 balls at different temperatures (RT, 550 and $700{ }^{\circ} \mathrm{C}$ ) are shown in Figure 2. No differences in the COF values are observed at room temperature for both coatings. Nevertheless, the friction values are lower than when tested against $\mathrm{Al}_{2} \mathrm{O}_{3}$ balls. Furthermore, the running-in stage for the reference coating lasted 250 cycles, while it was almost nonexistent for the Ag-containing coating. For the high-temperature tests, the COF of the Ag-containing coating was always lower than that of 
the reference coating by $29 \%$ and $24 \%$ for 550 and $700{ }^{\circ} \mathrm{C}$, respectively. In both cases, a slight decrease in the COF of the coatings was observed when testing from 550 to $700{ }^{\circ} \mathrm{C}$.
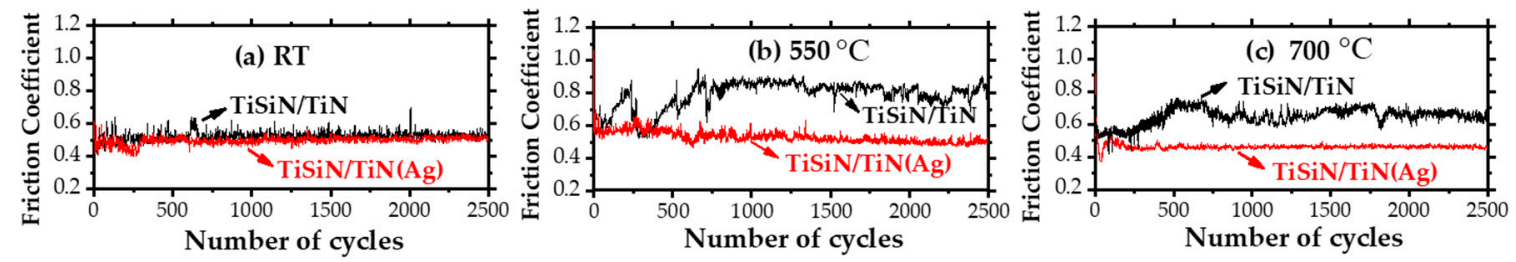

Figure 2. Friction coefficient (COF) of the reference and Ag-alloyed coatings as a function of the number of cycles tested against TiAl6V4 balls at (a) RT, (b) $550{ }^{\circ} \mathrm{C}$ and (c) $700{ }^{\circ} \mathrm{C}$.

\subsection{Specific Wear Rate of Coatings and Balls}

The specific wear rate of the coatings tested against the two counterparts at RT, 550 and $700{ }^{\circ} \mathrm{C}$ (the last temperature for the tests conducted against TiAl6V4 balls) is shown in Figure 3, along with the wear rate of the corresponding balls. The wear rates were calculated from the analysis of the wear scars of both the coated disks (2D profiles-Figure S1 of the Supplementary Material) and the balls (optical microscopy-Figure S2 of the Supplementary Material). As expected, and in accordance with the friction coefficient variation described above, the specific wear rate depends on the chemical composition of the coatings, testing temperature and counterpart material used.
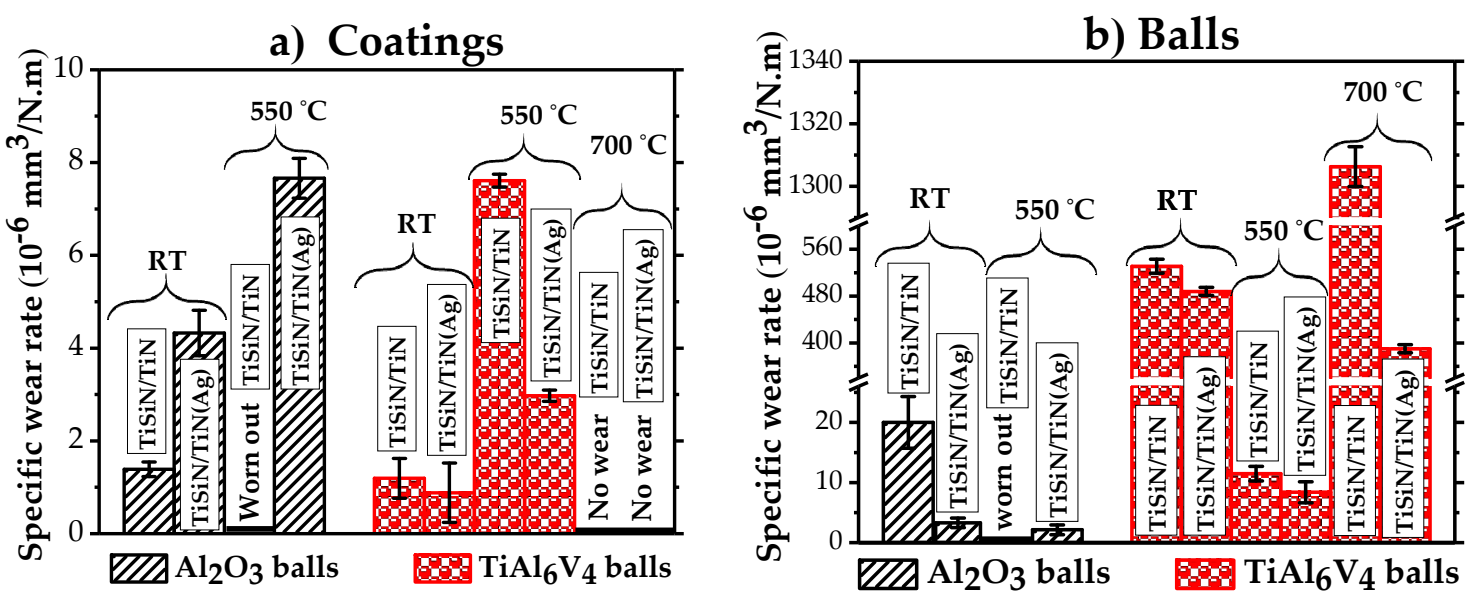

Figure 3. (a) Specific wear rate of the coatings tested against different balls, and (b) specific wear rate of $\mathrm{Al}_{2} \mathrm{O}_{3}$ tested at $\mathrm{RT}$ and $550{ }^{\circ} \mathrm{C}$ and TiAl6V4 balls tested at RT, 550 and $700{ }^{\circ} \mathrm{C}$.

\subsection{1. $\mathrm{Al}_{2} \mathrm{O}_{3}$ Balls}

The reference coating displayed a better wear performance at RT, which was expected due to its higher hardness and fracture toughness and low friction coefficient. A similar tendency was observed by Dang et al. [26] for multilayer TiSiN/Ag films containing a low Ag concentration (sliding against WC- 6 wt \% Co balls) and by Cavaleiro et al. [27] for TiSiN(Ag) monolayer films deposited by HiPIMS in DOMS mode sliding against $\mathrm{Al}_{2} \mathrm{O}_{3}$ balls. Despite the presence of $\mathrm{Ag}$ in the TiSiN/TiN(Ag) coating, the absence of a continuous Ag-rich tribolayer in the contact does not allow a decrease in the friction at $\mathrm{RT}$ and, consequently, is not able to counteract the influence of its worse mechanical properties on the wear resistance.

At $550{ }^{\circ} \mathrm{C}$, the $\mathrm{Ag}$ addition had a positive effect on the tribological performance of the coating. Despite the high specific wear rate, as compared to the RT test, the coating clearly outperformed the reference, which was worn out immediately. At a high temperature, the specific wear rate of the ball was almost negligible for the Ag-containing coating, which was primarily attributed to the decrease in the number of cycles and the formation of a protective Ag-rich tribolayer. 


\subsubsection{TiAl6V4 Balls}

At RT, the specific wear rate of the coatings tested against TiAl6V4 balls was lower when compared to $\mathrm{Al}_{2} \mathrm{O}_{3}$ balls, due to either the less severe contact promoted by the softer and less rigid TiAl6V4 ball or the presence of adherent material at the worn track, as will be shown later. The ball wear was extensive, leading to a rapid reduction of the contact pressure and thus minimizing the coating wear (Figure 3). The ball showed a slightly better wear resistance when sliding against the Ag-alloyed coating than against the reference one.

At $550{ }^{\circ} \mathrm{C}$, in spite of the masking effect of the adherent material, it was possible to observe deeper negative zones in the 2D profiles (Figure S1b from the Supplementary Material) when compared to the RT-tested samples, suggesting that the wear resistance was decreased. In this sense, Ag-alloyed coatings outperformed the reference coating. Surprisingly, the wear rate of the balls was two to three orders of magnitude lower than that of the RT tests. Again, the ball slide against the Ag-alloyed coating displayed a lower wear than the one tested against the reference one.

At $700{ }^{\circ} \mathrm{C}$, the wear of the coating was not measurable; conversely, the balls wore out extensively, particularly the one sliding against the reference coating. The increase in the wear rate of the ball at this temperature should be attributed to the significant decrease of the mechanical strength of the Ti-alloy at this temperature [28]. In summary, for both ball materials the Ag-alloyed coating performed better than the reference coating with an increasing temperature. Although there was no coating wear at $700{ }^{\circ} \mathrm{C}$, even in this case the addition of $\mathrm{Ag}$ was beneficial. It significantly limited the amount of adhered material on the worn coating surface and thus reduced the TiAl6V4 ball wear.

\section{Discussion}

To understand the behaviors of the friction and the wear described above, a detailed analysis of the wear mechanisms, including a wear debris characterization, was performed, and a detailed discussion follows below.

\section{1. $\mathrm{Al}_{2} \mathrm{O}_{3}$ Balls}

Figure 4 shows the typical wear track micrographs of TiSiN/TiN and TiSiN/TiN(Ag) coatings tested at RT. An EDS spectrum of the wear debris present at the reference coating wear track is also shown. Both coatings displayed relatively smooth wear tracks (see 2D profiles in Figure S1 in the Supplementary Material) predominantly indicating a polishing wear mechanism. Additionally, fish-like wear debris can be observed on the wear track of the reference coating, suggesting the plastic deformation of the coating; the EDS analysis revealed small peaks of $\mathrm{O}$ and $\mathrm{Al}$, suggesting a mixture of materials from the coating and debris from the ball. The ball wear scar was completely covered with debris of the same type (see Figure S2 of the Supplementary Material). On the other hand, such wear particles were almost absent from the wear track of the Ag-alloyed coating. The continuous sliding movement of the ball will drag the wear debris particles along the coating surface, contributing to the continuous removal of the coating. The wear of both coatings is governed by microabrasion. In the case of the reference TiSiN/TiN coating, plastic deformation of big-size debris can also occur, which is corroborated by the fluctuations of the friction shown in Figure 1a. However, the higher hardness and resistance to plastic deformation (see Table 1) result in lower wear when compared to the Ag-containing coatings. In tribological contact, when an abrasion mechanism is observed, the mechanical strength determines the wear resistance. At RT, Ag is not expected to directly influence the frictional behavior via the formation of a low-friction tribolayer. Ductile materials, such as Ag, only provide low friction at high temperatures $[25,26]$. Therefore, the wear rate is higher than for the reference coating. However, by contributing to the softening of the multilayer coating, it allows an easier production of smaller wear debris, avoiding the fluctuation in the COF observed in the TiSiN/TiN coating. Having formed similar tribolayers, with the exception of the presence of $\mathrm{Ag}$ in the TiSiN/TiN(Ag) coating, the COF values at the end of the tests are similar for both coatings. 

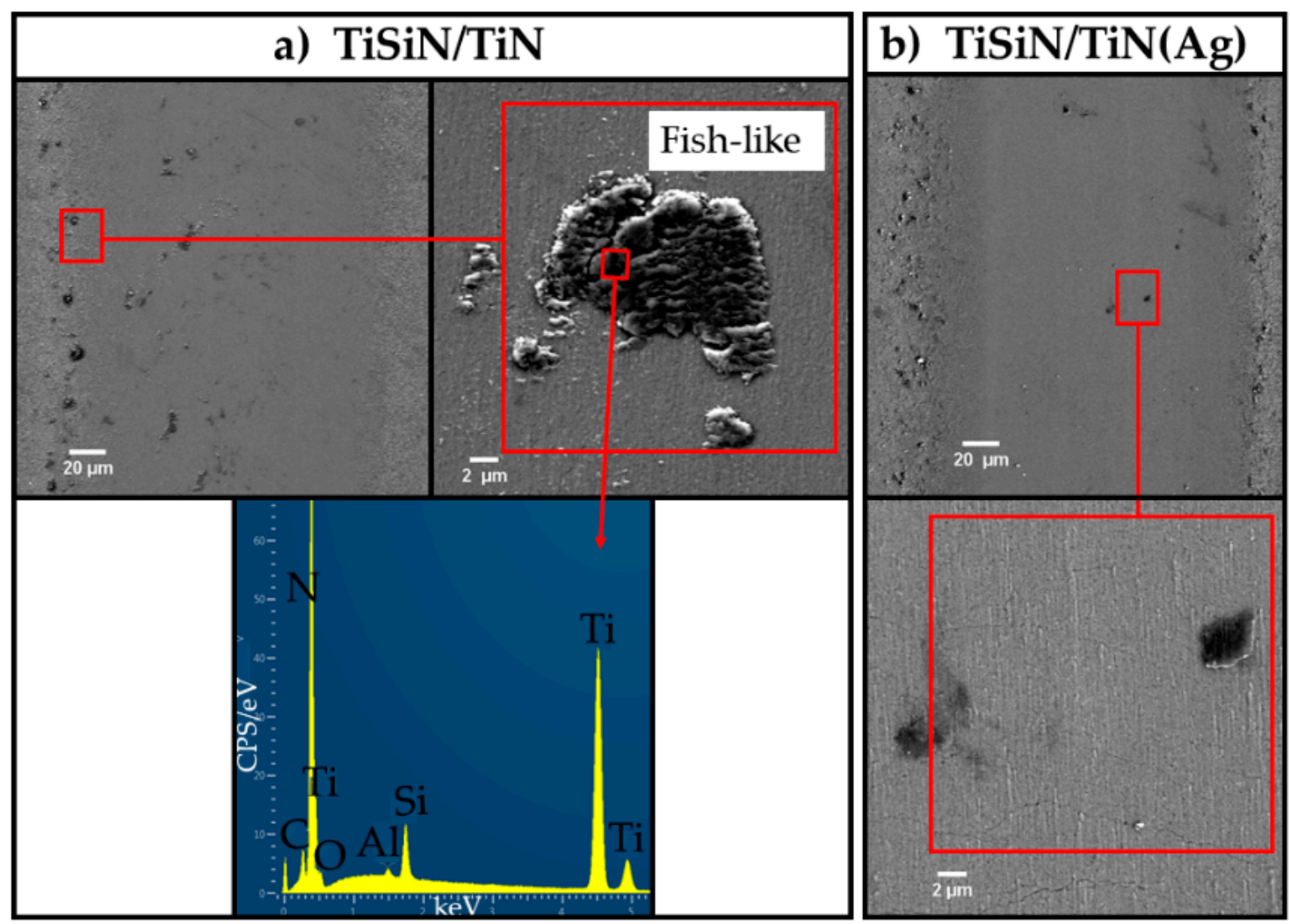

Figure 4. SEM micrographs of the wear tracks of the (a) reference and (b) Ag-alloyed coatings tested at RT against $\mathrm{Al}_{2} \mathrm{O}_{3}$ balls. In (a), the EDS spectrum of the wear debris visible on the wear track of the reference coating is also shown.

At $550{ }^{\circ} \mathrm{C}$, the reference coating was completely delaminated after the test start, resulting in a catastrophic coating failure (Figure 5a). On the other hand, the wear track of the Ag-alloyed coating (Figure $5 b$ ) showed a severe abrasion wear mechanism, with the majority of the wear debris ejected out to the wear track border. Similar to the RT tests, the wear track of this coating was also smooth (see Figure 5b). Nonetheless, some wear debris particles adhered in the wear track, with the ball counterpart completely covered with them (see the Supplementary Material). The EDS analysis conducted on such wear debris revealed $\mathrm{Ti}, \mathrm{Si}, \mathrm{Al}$ and $\mathrm{Ag}$, as well as a low amount of $\mathrm{O}$, suggesting the partial oxidation of the coating debris and/or debris from the alumina ball, together with Ag. Although a temperature higher than $550{ }^{\circ} \mathrm{C}$, motivated by the movement of the ball (flash contact temperature), was expected on the ball contact during the tribological tests, the partial oxidation of the wear debris agreed well with the higher onset point of oxidation measured for the coatings $\left(\sim 70{ }^{\circ} \mathrm{C}\right.$, see Table 1$)$. The counter body was fully covered with wear debris of this type. The production of the coating wear debris necessary for forming the tribolayer increased the coating wear rate in relation to the RT values, as could be shown by the higher amount of adhered material to the ball at $550{ }^{\circ} \mathrm{C}$ (compare the RT and $550^{\circ} \mathrm{C}$ results in the Supplementary Material). As shown before, the presence of Ag in the contact led to a decrease of the COF as compared to the RT test due to the less globally mechanical strength of the tribolayer at a high temperature. The presence of $\mathrm{Ag}$ in the contact will also decrease the shear stresses needed for the sliding, leading to a better tribological behavior of the Ag-rich coating as compared to the reference TiSiN/TiN coating, despite its lower mechanical properties. 


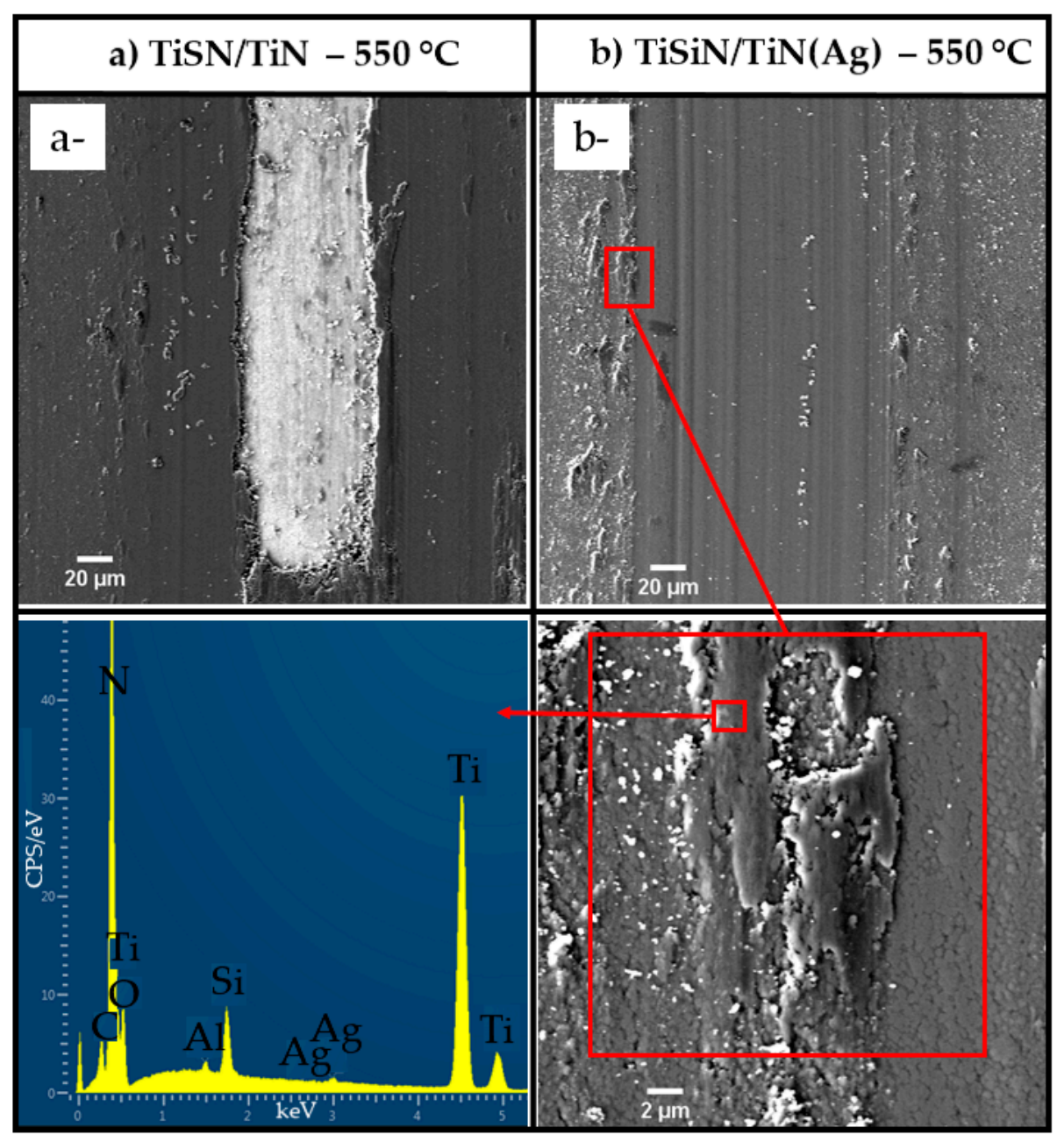

Figure 5. SEM micrographs of the wear tracks of the (a) reference and (b) Ag-alloyed coatings tested at $550{ }^{\circ} \mathrm{C}$ against $\mathrm{Al}_{2} \mathrm{O}_{3}$ balls. The magnification of the wear debris on the wear track of the Ag-doped coating; the corresponding EDS spectrum of those wear debris is plotted too.

\subsection{TiAl6V4 Balls}

Figure 6 shows the wear track of the coatings tested against TiAl6V4 balls at RT. It is clear that the wear is different to that from the testing against $\mathrm{Al}_{2} \mathrm{O}_{3}$ balls; the wear tracks are much rougher. The wear track of both coatings displayed typical adhesive wear with a very high amount of adhered material (see also the 2D profiles in Figure S1 of the Supplementary Material). The EDS analysis of both coatings revealed that the wear debris mainly consisted of $\mathrm{Ti}, \mathrm{Al}$ and $\mathrm{V}$, with minor traces of $\mathrm{O}$. In some cases, the wear particles also included elements from the coating, with signals from Ag in the case of the Ag-alloyed coating, as can be observed in Figure 6b. Since this ball material is much softer than $\mathrm{Al}_{2} \mathrm{O}_{3}$, the much harder material from the coating causes extensive ball wear. The surface facies of the ball crater indicate a typical abrasion mechanism. The wear volumes in the balls were similar in the tests with both coatings. As the test progresses, material from the ball will be transferred to the coating surface, creating a continuous adhesive layer at the coating surfaces that protects them from further wear. The low amount of $\mathrm{O}$ indicates that the adhered material is nonoxidized. Thus, the established contact during sliding is between the material from the ball adhered to the coating and the ball material, i.e., Ti6Al4V sliding against itself. Then, similar COF values are measured, as shown in Figure 2. As the contact was similar and the wear mainly occurred in the ball, similar ball wear rates were also achieved in the tests with both coatings. 


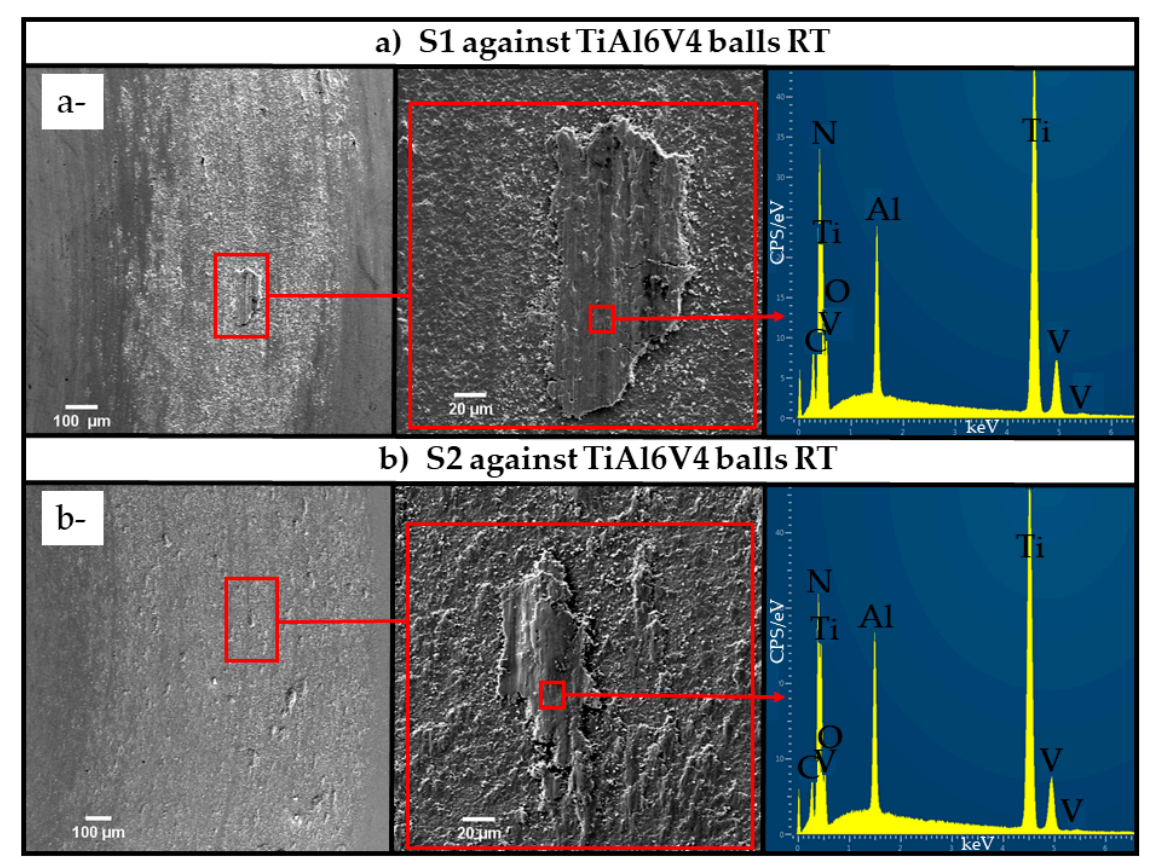

Figure 6. SEM micrographs of the wear tracks and wear debris, and the corresponding EDS analysis for the (a) reference and (b) Ag-alloyed coatings tested at RT against TiAl6V4 balls.

The wear track of the reference coating tested at $550{ }^{\circ} \mathrm{C}$ points is similar to the wear mechanism at RT, with adhered material in the wear track. However, the EDS analysis in Figure 7a shows a significant difference in the chemical composition: a strong $\mathrm{O}$ peak is detected, meaning that the adhered material is oxidized, suggesting the presence of a complex mixture of oxides. Similar oxides also adhered to the ball counterpart (see Figure S2 of the Supplementary Material). Therefore, in relation to RT, the main difference in the sliding process is that the contact is now between TiAlV-oxide and TiAlV-oxide, which can explain both the significant changes encountered for either the COF and the wear rate. The COF increase to 0.8 is due to the change in the materials in the contact. On the other hand, the partial coverage of the ball with oxide debris protects the underlayer material from wear, decreasing the wear rate of the ball in relation to the RT test.

A distinct wear behavior was found for the Ag-alloyed coating. Several grooves parallel to the direction of sliding were visible together with areas covered by the adhered material, suggesting a mixture of abrasion and adhesion wear mechanisms. The adhered particles were mostly composed of $\mathrm{Ti}, \mathrm{Si}, \mathrm{O}$ and $\mathrm{Ag}$; the near-absence of $\mathrm{Al}$ suggested that the ball material transfer and adherence to the wear track were negligible. The low signal of $\mathrm{O}$ meant that the wear debris were mainly not oxidized, in good agreement with the higher onset point of oxidation of the coating, i.e., $700{ }^{\circ} \mathrm{C}$ (see Table 1 ). In the smooth parts of the wear tracks, Ag particles could be observed at the surface (see Figure $7 \mathrm{~b}$ ), which should be the origin for the nonadherence of wear debris from the ball. Moreover, the material that adhered to the ball wear scar showed a similar composition, indicating a transfer from the coating to the ball. These observations suggested that the contact was significantly different from the reference coating, i.e., it should be of a $\operatorname{TiSiN}(\mathrm{Ag})(\mathrm{O})$ and/or $\operatorname{TiSiN}(\mathrm{Ag})(\mathrm{O})+\operatorname{TiAlV}(\mathrm{O})$ type, which justified the much lower COF. The presence of debris of oxidized ball material on the wear track of the coated sample should not be discarded. As referred to above for the reference coating tested at $550{ }^{\circ} \mathrm{C}$, the TiAl6V4 ball tested against the Ag-containing sample at this temperature also had a much lower wear rate when compared to the RT conditions, since it was partially covered with wear debris protecting the surface against the wear. 


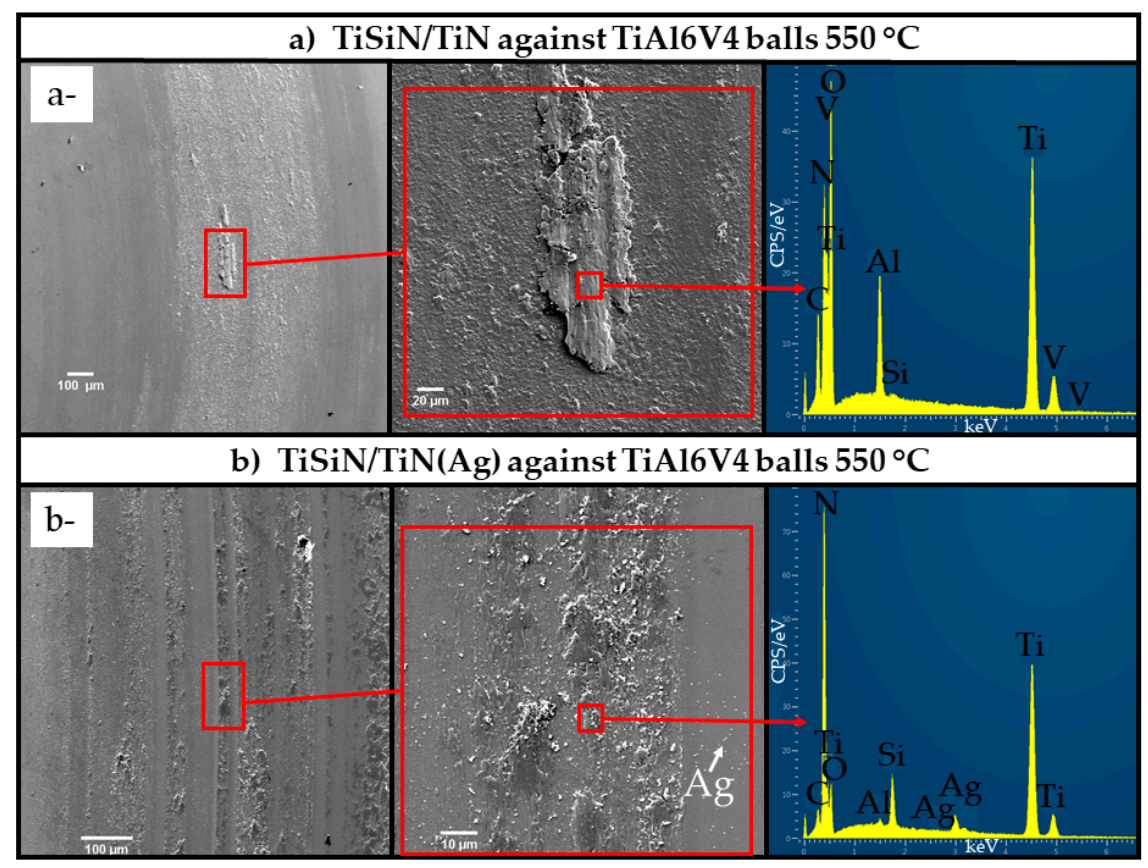

Figure 7. SEM micrographs of the wear tracks and wear debris, and the corresponding EDS analysis for the (a) reference and (b) Ag-doped coatings tested at $550{ }^{\circ} \mathrm{C}$ against Tial6V4 balls.

In summary, the wear processes at $550{ }^{\circ} \mathrm{C}$ for the reference and Ag-doped coatings can be summarized as follows. At the beginning of the test, particles from either the ball or the coatings detach, with a high quantity of material from the softer ball. When the wear debris are stuck in the contact, the simultaneous action of the temperature and stress promotes their oxidation, which is very strong in the case of the Ti-alloy and very light in the coatings' material due to their high oxidation resistance [19]. The difference between the two coatings is that the presence of Ag hinders the adherence of the Ti-alloy debris to the coating, contrarily to the case of the reference coating. Therefore, as the test progresses, a continuous Ti-Al-V-O layer, originating from the ball material, is established at either the surface of the reference coating or the counterpart, protecting the coating and the ball from strong wear but increasing the COF value in relation to the RT tests. In the case of the Ag-doped coating, the presence of silver prevents the adhesion of the oxidized Ti-alloy wear debris in the contact, favoring the adhesion of wear debris from the coating to both elements of the sliding pair. The protection against wear is enhanced, and the COF will be closer to the RT values but slightly lower due to the decrease of the mechanical strength of the materials with the temperature.

When testing at $700{ }^{\circ} \mathrm{C}$, the reference coating showed a wear mechanism similar to that for $550{ }^{\circ} \mathrm{C}$, with the oxidized material from the ball adhering to the wear track (Figure 8a). In Figure S3 in the Supplementary Material, a 3D wear track of the reference coating was plotted, where spikes were observed coming out for the original level of the coating, confirming the near-inexistence of wear. The material transferred from the ball to the surface of the coating worked as a protective tribolayer that helped avoid the coating's wear. However, inversely to what was observed at $550{ }^{\circ} \mathrm{C}$, no adhesion of the wear debris to the ball was observed. Therefore, no protection for the ball existed, and a strong wear took place on this element of the sliding pair (see Figure $3 \mathrm{~b}$ and Figure S2 of the Supplementary Material). Although we could not find the mechanical strength of Ti6Al4V at $700{ }^{\circ} \mathrm{C}$, at $550{ }^{\circ} \mathrm{C}$ it decreased by half in relation to RT, and by extrapolation at $700{ }^{\circ} \mathrm{C}$ it would be one order of magnitude lower than at RT [29]. Then, the ball material would be strongly removed during the sliding process. On the other hand, almost no adhered material could be detected at the Ag-alloyed coating wear track (Figure 8b), and the few wear debris observed there were not from the ball material. A closer analysis of this zone allowed one to easily perceive the presence of white agglomerated particles evenly distributed along the wear track, including in the wear debris, which the EDS analysis revealed to be 
Ag. These wear debris were also observed to have adhered to the wear scar in the ball, although at a lower amount than for the $550{ }^{\circ} \mathrm{C}$ test. This presence helped protect the ball from wear, although not as efficiently as for $550^{\circ} \mathrm{C}$, leading to a lower wear rate of the TiAl6V4 ball than the one found for the reference coating at $700{ }^{\circ} \mathrm{C}$ (see Figure 3b). Additionally, the Ag particles will also decrease the friction and protect the film from wear.

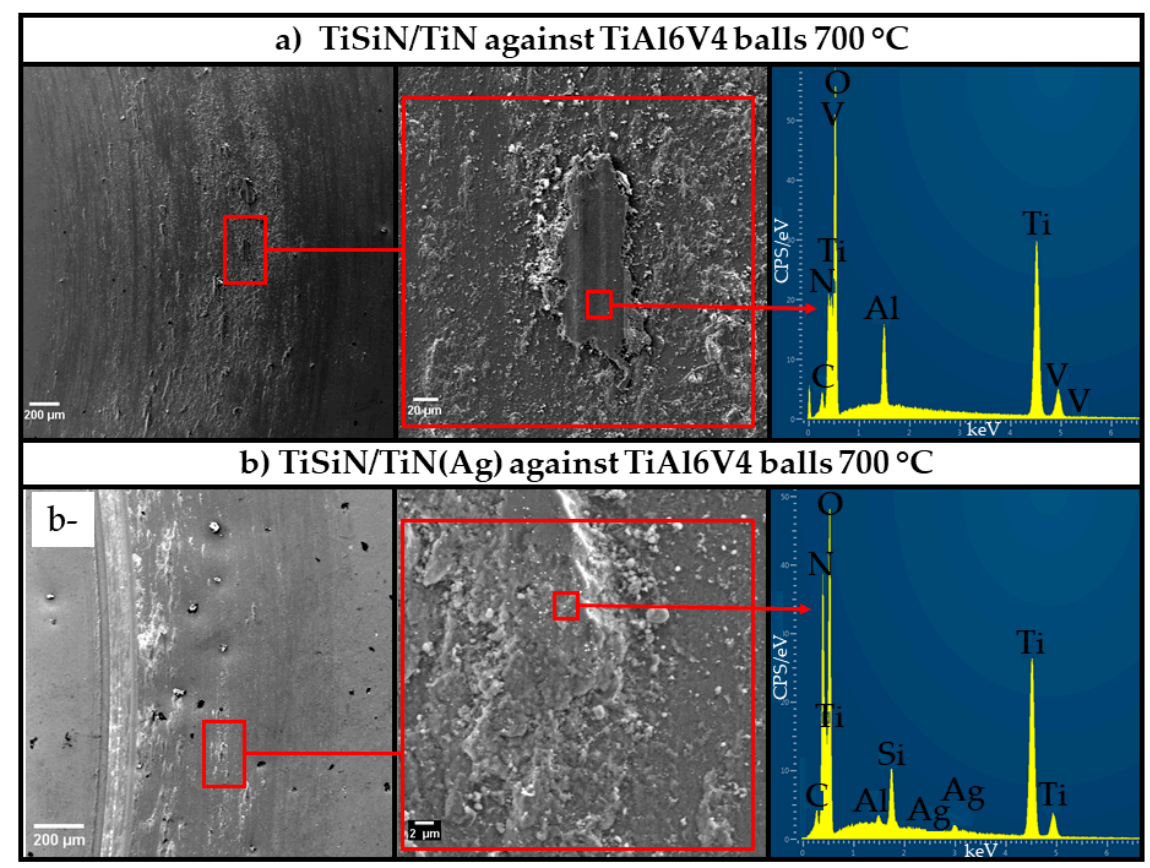

Figure 8. SEM micrographs of the wear tracks of the (a) reference and (b) Ag-doped coatings, tested at $700{ }^{\circ} \mathrm{C}$ against TiAl6V4 balls. The EDS spectrum of wear debris detected in the wear track of the coatings is plotted too.

In summary, the presence of silver in the sliding contact acts as a lubricious element, effectively reducing the wear and friction (as later shown in Figure 2c). The results showed that silver helped in the formation of a protective tribolayer and stopped the material that adhered to the surface of the ball. This is an interesting result since it eliminates one of the most common machining failures of titanium alloys, which is the formation of built-up edges. Thus, TiSiN/TiN(Ag) coating may be a promising coating system for extending the lifetime of the machining tools used for cutting Ti alloys under dry conditions [29]. Machining studies are being planned to achieve further insight into coatings' cutting performance.

\section{Conclusions}

The present work reports on the room and high-temperature tribological performance of multilayered TiSiN/TiN and TiSiN/TiN(Ag) coatings deposited on WC-6 wt.\% Co substrates by $\mathrm{DC}$ reactive sputtering. The tribological tests were conducted in a high temperature pin-on-disk tribometer at room temperature and $550{ }^{\circ} \mathrm{C}$ sliding against $\mathrm{Al}_{2} \mathrm{O}_{3}$ balls, and at room temperature, 550 and $700{ }^{\circ} \mathrm{C}$ sliding against TiAl6V4 balls. The wear mechanisms and wear debris were characterized by scanning electron microscopy (SEM) and energy dispersive X-ray spectroscopy (EDS), and were correlated with the friction coefficient and wear rate values of the coatings and balls. The main results can be summarized as follows for each type of counterpart:

Sliding against $\mathrm{Al}_{2} \mathrm{O}_{3}$ balls:

- Sliding against $\mathrm{Al}_{2} \mathrm{O}_{3}$ balls led to the formation of relatively smooth wear tracks at RT.

- The reference coating displayed a better performance due to its high hardness and fracture toughness as compared to the Ag-alloyed coating. 
- At $550{ }^{\circ} \mathrm{C}$, the reference coating failed, while the Ag-doped coating showed a better performance due to the presence of $\mathrm{Ag}$ on the contact, which decreased the shear strength and consequently the friction.

Sliding against TiAl6V4 balls:

- Ag-doped coating was always better than reference coating.

- At room temperature, the wear was governed by the contact between the material from the ball adhering to the coating and the ball material, i.e., TiAl6V4 sliding against itself.

- At $5500^{\circ} \mathrm{C}$, the presence of $\mathrm{Ag}$ at the contact prevented the adhesion of the oxidized Ti-alloy wear debris in the contact, favoring the adhesion of wear debris from the coating to both elements of the sliding pair and thus leading to a better performance.

- No wear could be observed at $700{ }^{\circ} \mathrm{C}$ for both coatings. However, whilst spikes coming out from the wear track of the reference coating could be detected, suggesting a strong adhesion wear mechanism, the wear track of the Ag-doped coating displayed a smooth surface that was almost absent of adhesion wear.

- The presence of Ag-agglomerated particles on the wear track of the TiSiN/TiN(Ag) coating decreased friction and hindered the adhesion of material to the wear track.

Supplementary Materials: The following are available online at http://www.mdpi.com/2079-6412/10/12/1191/s1, Figure S1: 2D profiles of coatings wear track tested against: (a) $\mathrm{Al}_{2} \mathrm{O}_{3}$ and (b) TiAl6V4 balls, Figure S2: Optical images of the balls' wear zones, Figure S3: 3D profile of TiSiN/TiN reference film tested at $700{ }^{\circ} \mathrm{C}$ against TiAl6V4 balls, showing spikes coming out from the surface due to the adhesion of the material from the ball to the film surface.

Author Contributions: Conceptualization, F.F. and A.A.-R.; Funding acquisition, F.F.; Investigation, F.F., A.A.-R. and D.C.; Methodology, A.A.-R.; Project administration, F.F.; Supervision, A.C.; Validation, A.A.-R. and D.C.; Writing —original draft, F.F. and A.A.-R.; Writing—review \& editing, T.P. and A.C. All authors have read and agreed to the published version of the manuscript.

Funding: This research is sponsored by FEDER funds through the program COMPETE-Programa Operacional Factores de Competitividade-and by national funds through FCT-Fundação para a Ciência e a Tecnologia-under the projects: CEMMPRE—ref. "UIDB/00285/2020", SMARTLUB—ref. "POCI-01-0145-FEDER-031807", CONTROLLUB-UT Austin Portugal Program ref. “UTAP-EXPL/NTec/0107/2017" and MCTool21 "POCI-01-0247-FEDER-045940". This research was also supported by the projects CZ.02.2.69/0.0/0.0/18_070/0010457 and CZ.02.1.01/0.0/0.0/16_026/0008396.

Conflicts of Interest: The authors declare no conflict of interest. The funders had no role in the design of the study; in the collection, analyses, or interpretation of data; in the writing of the manuscript, or in the decision to publish the results.

\section{References}

1. Khanna, N.; Davim, J. Design-of-experiments application in machining titanium alloys for aerospace structural components. Measurement 2015, 61, 280-290. [CrossRef]

2. Arrazola, P.-J.; Garay, A.; Iriarte, L.-M.; Armendia, M.; Marya, S.; Le Maitre, F. Machinability of titanium alloys (Ti6Al4V and Ti555.3). J. Mater. Process. Technol. 2009, 209, 2223-2230. [CrossRef]

3. Dandekar, C.R.; Shin, Y.C.; Barnes, J. Machinability improvement of titanium alloy (Ti-6Al-4V) via LAM and hybrid machining. Int. J. Mach. Tools Manuf. 2010, 50, 174-182. [CrossRef]

4. Çalışkan, H.; Küçükköse, M.; Çaliskan, H. The effect of aCN/TiAlN coating on tool wear, cutting force, surface finish and chip morphology in face milling of Ti6Al4V superalloy. Int. J. Refract. Met. Hard Mater. 2015, 50, 304-312. [CrossRef]

5. Pramanik, A. Problems and solutions in machining of titanium alloys. Int. J. Adv. Manuf. Technol. 2014, 70, 919-928. [CrossRef]

6. Filho, S.L.M.R.; Lauro, C.H.; Bueno, A.H.S.; Brandão, L.C. Influence cutting parameters on the surface quality and corrosion behavior of Ti-6Al-4V alloy in synthetic body environment (SBF) using Response Surface Method. Measurement 2016, 88, 223-237. [CrossRef]

7. Veiga, C.; Davim, J.P.; Loureiro, A.J.R. Review on machinability of titanium alloys: The process perspective. Rev. Adv. Mater. Sci. 2013, 34, 148-164. 
8. Polishetty, A.; Goldberg, M.; Littlefair, G.; Puttaraju, M.; Patil, P.; Kalra, A. A preliminary assessment of machinability of titanium alloy Ti 6AL 4V during thin wall machining using trochoidal milling. Procedia Eng. 2014, 97, 357-364. [CrossRef]

9. Renevier, N.; Hamphire, J.; Fox, V.; Witts, J.; Allen, T.R.; Teer, D. Advantages of using self-lubricating, hard, wear-resistant $\mathrm{MoS}_{2}$-based coatings. Surf. Coat. Technol. 2001, 142-144, 67-77. [CrossRef]

10. Voevodin, A.; Muratore, C.; Aouadi, S. Hard coatings with high temperature adaptive lubrication and contact thermal management: Review. Surf. Coat. Technol. 2014, 257, 247-265. [CrossRef]

11. Cavaleiro, D.; Carvalho, S.; Fernandes, F. TiSiN(Ag) films deposited by HiPIMS working in DOMS mode: Effect of Ag content on structure, mechanical properties and thermal stability. Appl. Surf. Sci. 2019, 478, 426-434. [CrossRef]

12. Dang, C.; Li, J.; Wang, Y.; Yang, Y.; Wang, Y.; Chen, J. Influence of Ag contents on structure and tribological properties of TiSiN-Ag nanocomposite coatings on Ti-6Al-4V. Appl. Surf. Sci. 2017, 394, 613-624. [CrossRef]

13. Fernandes, F.; Yaqub, T.; Cavaleiro, A. Influence of Ag additions on the structure, mechanical properties and oxidation behaviour of Cr-O coatings deposited by HiPIMS. Surf. Coat. Technol. 2018, 339, 167-180. [CrossRef]

14. Moszner, F.; Cancellieri, C.; Chiodi, M.; Yoon, S.; Ariosa, D.; Janczak-Rusch, J.; Jeurgens, L.P.H. Thermal stability of $\mathrm{Cu} / \mathrm{W}$ nano-multilayers. Acta Mater. 2016, 107, 345-353. [CrossRef]

15. Li, J.-L.; Xiong, D. Tribological properties of nickel-based self-lubricating composite at elevated temperature and counterface material selection. Wear 2008, 265, 533-539. [CrossRef]

16. Zhu, S.; Cheng, J.; Qiao, Z.; Yang, J. High temperature solid-lubricating materials: A review. Tribol. Int. 2019, 133, 206-223. [CrossRef]

17. Aouadi, S.M.; Gao, H.; Martini, A.; Scharf, T.; Muratore, C. Lubricious oxide coatings for extreme temperature applications: A review. Surf. Coat. Technol. 2014, 257, 266-277. [CrossRef]

18. Bilger, G.; Voss, T.; Schlenker, T.; Strohm, A. High-temperature diffusion barriers from Si-rich silicon-nitride. Surf. Interface Anal. 2006, 38, 1687-1691. [CrossRef]

19. Al-Rjoub, A.; Cavaleiro, A.; Fernandes, F. Influence of Ag alloying on the morphology, structure, mechanical properties, thermal stability and oxidation resistance of multilayered TiSiN/Ti(Ag)N films. Mater. Des. 2020, 192, 108703. [CrossRef]

20. Archard, J.F. Contact and Rubbing of Flat Surfaces. J. Appl. Phys. 1953, 24, 981-988. [CrossRef]

21. Fernandes, F.; Polcar, T.; Cavaleiro, A. Tribological properties of self-lubricating TiSiVN coatings at room temperature. Surf. Coat. Technol. 2015, 267, 8-14. [CrossRef]

22. Ju, H.; Yu, L.; Yu, D.; Asempah, I.; Xu, J. Microstructure, mechanical and trobological properties of TiN-Ag films deposited by reactive magnetron sputtering. Vaccum 2017, 141, 82-88. [CrossRef]

23. Chang, C.-L.; Chen, W.-C.; Tsai, P.-C.; Ho, W.-Y.; Wang, D.-Y. Characteristics and performance of TiSiN/TiAlN multilayers coating synthesized by cathodic arc plasma evaporation. Surf. Coat. Technol. 2007, 202, 987-992. [CrossRef]

24. Wan, Q.; Yang, B.; Chen, Y.; Cai, Y.; Liu, Y.; Meng, L.; Gao, D. Effect of bilayer period on microstructure and mechanical properties of TiSiN/TiN coatings. Materialia 2018, 3, 260-264. [CrossRef]

25. Köstenbauer, H.; Fontalvo, G.A.; Mitterer, U.-P.D.-I.D.M.C.; Keckes, J. Tribological properties of TiN/Ag nanocomposite coatings. Tribol. Lett. 2008, 30, 53-60. [CrossRef]

26. Dang, C.; Dong, M.; Li, J.-L. Influence of annealing temperature on film morphology and tribological performance of TiSiN-Ag coating. Mater. Res. Express 2019, 6, 096446. [CrossRef]

27. Cavaleiro, D.; Veeregowda, D.; Carvalho, S.; Fernandes, F. High temperature tribological behaviour of TiSiN(Ag) films deposited by HiPIMS in DOMS mode. Surf. Coat. Technol. 2020, 399, 126176. [CrossRef]

28. Fan, Y.; Tian, W.; Guo, Y.; Sun, Z.; Xu, J. Relationships among the microstructure, mechanical properties, and fatigue behavior in thin Ti6Al4V. Adv. Mater. Sci. Eng. 2016, 2016, 7278267. [CrossRef]

29. Bandyopadhyay, B. Mechanism of formation of built-up edge. Precis. Eng. 1984, 6, 148-151. [CrossRef]

Publisher's Note: MDPI stays neutral with regard to jurisdictional claims in published maps and institutional affiliations. 